\title{
PHENOLOGICAL MONITORING AT ROYAL BOTANIC GARDEN EDINBURGH
}

\author{
G.H. HARPer, D.G. MANN \& R. THOMPSON*
}

\begin{abstract}
Phenological monitoring at the Royal Botanic Garden Edinburgh (RBGE) began in the mid 19th century, and is now being developed as a number of projects. In view of the wide range of plantclimate interactions, it is recommended that projects are designed with clear and limited objectives, and are then conducted consistently and to a high standard over a long period. The projects at RBGE are outlined, and the suitability of botanic gardens in general for phenology is discussed. A distinction is drawn between 'organism phenology' and 'population phenology', and also between 'extensive' and 'intensive' approaches to project design. The variety of possible projects is illustrated by a number of completed and on-going projects in the UK, USA and northern Eurasia. It is suggested that botanic gardens can enhance their service to society by becoming phenological monitoring stations.
\end{abstract}

\section{INTRODUCTION}

Phenology is the study of seasonal phenomena. The ties between phenology and taxonomic botany have a venerable history. No-one doubts that Linnaeus is the 'father' of modern botanical nomenclature, but he has also been credited with introducing the word 'phenology' (Gunn, 2003); of course, many others before him had made phenological observations, e.g. of the dates of wine harvests (Ladurie \& Baulant 1981). In his Philosophia Botanica Linnaeus listed dates for first flowering, leafing, fruiting and leaf fall, and recommended that 'Floral calendars should be completed every year in every province, according to the leafing, flowering, fruiting and leaf-shedding, with simultaneous observations of the climate, so that it may be ascertained how regions differ among themselves' (Linnaeus 1751, p. 297).

The history of an interest in climate-plant interactions at the Royal Botanic Garden Edinburgh (RBGE) dates from about a century later, when the first phenological project (or at least, the first of which we have a record) was set up in the Garden. It is the purpose of this article to discuss the role of phenological research at RBGE and in botanic gardens in general. After a brief review of the potential scope of phenology, past and current projects at RBGE will be described along with a discussion of botanic gardens as sites for phenological study.

\footnotetext{
${ }^{*}$ Geoff Harper is a member of the Science staff at RBGE, working on the Pandora Rosaceae database, and is also a part-time volunteer phenologist. Address: Royal Botanic Garden Edinburgh, 20A Inverleith Row, Edinburgh EH3 5LR. E-mail g.harper@rbge.org.uk

David Mann is a member of the Science staff at RBGE, leading research on diatoms. Address as above. Email d.mann@rbge.org.uk

Roy Thomson is Professor of Geology in the Department of Geology and Geophysics at the University of Edinburgh. Address: Department of Geology and Geophysics, Edinburgh University, West Main Road, Edinburgh, EH93JW.E-mail roy@ed.ac.uk
} 


\section{SCOPE OF PHENOLOGY}

Phenology has long had a high public profile, if only in the form of the annual letters to The Times announcing the first cuckoo of spring. Observations of bird migration, frog spawning, butterfly flight activity and even mowers mowing (for which, see the UK Phenology Network: http://www.phenology.org.uk/) relate largely to animal behaviour, but plant behaviour of phenological interest is intimately linked with growth and development. Events of importance - including sap rise, bud burst, leaf expansion, shoot expansion, flowering, fruiting, yellowing of leaves and leaf fall - result from growth and development of buds and their products. For this reason alone plant phenology extends into many areas of plant science. Unlike homoiothermic animals, plants are heavily influenced by external environmental factors, including most of those contributing to the weather, so that plant phenology also overlaps to a large extent with plant-environment relations in general, or, in other words, ecology.

In principle, therefore, a wide range of benefits can be expected from phenological studies. The recent reawakening of interest in phenology is largely due to the perceived impact of climate change on plant and animal behaviour. Most popular treatments of modern phenology in the mass media use organisms as indicators of climate change, and usually involve reports of early flowering or the early arrival of migratory birds. There is a clear educational value in such media attention, and public interest is likely to be maintained over many years by such exposure. However, such limited reports may also do some harm by conveying the simplistic notion that climate change merely means climate warming, and that earlier dates are the most that can be expected.

Studies of plant-climate interactions are mostly concerned with the effects of weather on plants. The beginning and end of flowering are two of the most easily measured phenological parameters, but some of the others listed above, although more difficult (or perhaps impossible) to measure to an adequate standard, may be more important. Fruit-growers, of course, are interested in the timing as well as the quantity and quality of yield. The timing of bud-burst in relation to frosts has profound implications for plant growth and health as well as for flowering and fruiting. Methods are being tested at RBGE for measuring bud-burst, the start and end of shoot elongation, and leaf-fall in apple trees.

Weather may affect more than one aspect of a given plant's growth and development. A classic case of this is the interaction of chilling and 'thermal time' (the summation of temperatures exceeding a given threshold over a period of time). If both factors are affected by changing conditions, the implications for time of bud-burst or flowering may be complex (e.g. Murray et al., 1989).

Plant-climate interactions also include the effects of plants on climate. Although rather less attention has previously been paid to this, as opposed to the effects of climate on plants, it is a key component in earth-system science. The annual cycle of $\mathrm{CO}_{2}$ concentration in the atmosphere of the northern hemisphere is a clear example (see data in 'Online trends: a compendium of data on global change' at http://cdiac.esd.ornl.gov/trends/co2/sio-keel.htm), and the timing of the rising phase in the cycle can be expected to depend on the onset of the growing period in ecologically important species, just as the magnitude of the effect will be affected by the duration of the growing period. Leaf expansion and leaf fall or die-back, marking approximately 
the start and end of $\mathrm{CO}_{2}$-assimilation by non-evergreen species, also affects the planet's albedo (its 'whiteness', i.e. its capacity to reflect rather than absorb radiation), so influencing the energy balance of the atmosphere and vegetation layer.

With influences in both directions between plants and climate, it can be appreciated that interactions can be extremely complex. This is underlined by the realisation that climate involves a wide number of important variables - such as temperature, insolation, humidity, precipitation, and wind direction and strength. Significant climate change will involve some or all of these. Of particular ecological importance may be the increase, decrease or timing of extreme events - such as droughts, high winds, or unusually high or low temperatures. Thus, while generalised parameters such as global mean temperature or annual rainfall have their uses in climatology, they are not likely to help explain the fine details in the phenological behaviour of organisms. Phenologists must therefore handle data at a much higher resolution, and this means of course that a correspondingly greater volume of information must be collected and analysed.

It has been argued so far that the scope of phenology as a branch of science is almost limitless in terms of the amount of potentially useful information that can be collected. Any practical project to record phenological data will therefore have some value, but it will make a major contribution to knowledge only if the data-set is coherent and is assembled over a long period. This is likely to be achieved only if the project is well defined and focussed, with a view to shedding light on a particular aspect of organism-environment interactions. (This is discussed further in the section on botanic gardens.)

Phenology does not generally fit the common pattern of hypothesis-driven research projects supported by short-term funding, like those grants awarded from the UK science research councils. Phenology is, by its nature, a matter of monitoring consistently over the long term and the aims of recording, though clear, may not be specific, in the sense of testing a particular conjecture. The collection and archiving of meteorological observations provides an excellent model, which has operated for more than a century. Here and elsewhere, long-term monitoring is the only way to detect and allow for the chance or extreme events that play such an important role in ecology.

The value of long-term monitoring of bird populations by organisations like the British Trust for Ornithology has recently been recognised by the British Government, and bird-population indices are now incorporated into measures of the quality of the environment. Phenology, then, embraces a very different style of science from the short-term hypothesis-driven approach, but one essential for understanding how the biosphere functions. For that very reason, it can be expected to increase in importance as governments and international organisations struggle to cope with the pressure of human population on the environment and with anthropogenically driven climate change.

\section{PHENOLOGY AT THE ROYAL BOTANIC GARDEN EDINBURGH}

Phenology appears to have begun in Edinburgh not long after Linnaeus' clarion call to the phenologists of Sweden. A work associated with John Hope lists the flowering dates of many species around Edinburgh in 1764 and 1765 (Anonymous 1765). About 20 of these species are being monitored today in the RBGE 'daily' project. 
The earliest phenological data recorded specifically from the Royal Botanic Garden itself, at its present site at Inverleith, are the first-flowering dates of 24 plants in 1850 . 'In the Edinburgh Botanic Garden, $\mathrm{Mr} \mathrm{McNab}$ for many years kept a register of the flowering of spring plants, selecting year after year the same specimens, in the same localities, and with the same exposure' (Balfour, 1863, p.73). James McNab (Plate 2a) continued recording the first-flowering dates of some 90 species until 1878. Thereafter the work was continued by the next two Curators: John Sadler until 1882, and then Robert Lindsay until 1895, when recording may have ceased. Sadler and Lindsay concentrated their efforts on 40 of the McNab species and the records of their observations are to be found in various volumes of the Transactions \& Proceedings of the Botanical Society of Edinburgh (e.g. McNab 1857, Sadler 1879, 1882, Lindsay 1893). Good photographic material that shows the layout of RBGE in the mid to late $1800 \mathrm{~s}$ is available in the RBGE archives. Plate $2 \mathrm{~b}$ is an example, showing the Rock Garden after rebuilding and landscaping in the $1860 \mathrm{~s}$.

Monitoring was continued in the 20th century, and handwritten records exist in the RBGE archives for weekly or monthly observations between 1906 and 1939, often throughout the whole calendar year. While these data have the disadvantage that they were not collected daily, they do record flowering duration, since the sheets list all plants in flower on a given date, not just the first date of flowering. Unfortunately no records have been found for the period between 1940 and 2000, although phenological observations continued to be made at RBGE after World War 2 (E.E. Kemp, the late A. Evans, personal communication). We fear that the records were destroyed in the $1960 \mathrm{~s}$. There is a clear lesson here on data archiving and stewardship.

Provisional analysis by one of us (R.T.) and his students has shown that almost $90 \%$ of the taxa monitored in the 19th century and probably well over half those monitored in the 20th century are temperature sensitive. Whether deliberately or not, the 19thand 20th-century projects managed to select a large number of potential indicators of climate change. Figure 1, on the next page, summarises the average first flowering date for 66 taxa in the second half of the 19th century. Note how all the unusually early or unusually late flowerings are associated with temperature effects.

It is not entirely clear why phenological records were kept by RBGE staff between 1850 and 1939. What is certain, however, is that a number of people had a serious interest in the weather, and even in climate change, in relation to plants. As early as 1861 the Regius Keeper (director) of RBGE, Prof. J.H. Balfour, was recommending 'that accurate meteorological observations should be made in our botanical institutions. Our gardens ought to be supplied with good instruments, and our gardeners trained to accuracy in observing' (Balfour 1861, p.58). He went on to make detailed remarks about plants' responses to temperature, which need to be borne in mind even today as we develop models on which to base analysis of phenological data. In particular there is a discussion of the minimum temperatures required by plants for various activities, such as germination, growth and flowering, and he recognised that different species and different activities may have different thresholds.

In the next decade, James McNab was writing actively about the possibility of climate change (e.g. McNab 1873). In fact he thought that the climate was deteriorating, although it is now clear that the mid-19th century was the end of the 'Little Ice Age' and the beginning of the warming trend that continues to the present day (a counter argument to McNab's suggestion of climate worsening was given by 
Buchan 1875, who considered that the available meteorological data showed no change during the later 18th and early 19th centuries). There can be little doubt that interest in climate change was a major motivation for continuing the phenological observations at RBGE in the 19th century, just as it is today. Indeed, the considerable interest in phenology and climate change among Edinburgh botanists in the 19th century was part of a wider picture, since Balfour referred to a committee appointed by the British Association to promote phenology, and there was similar activity on the continent at this time.

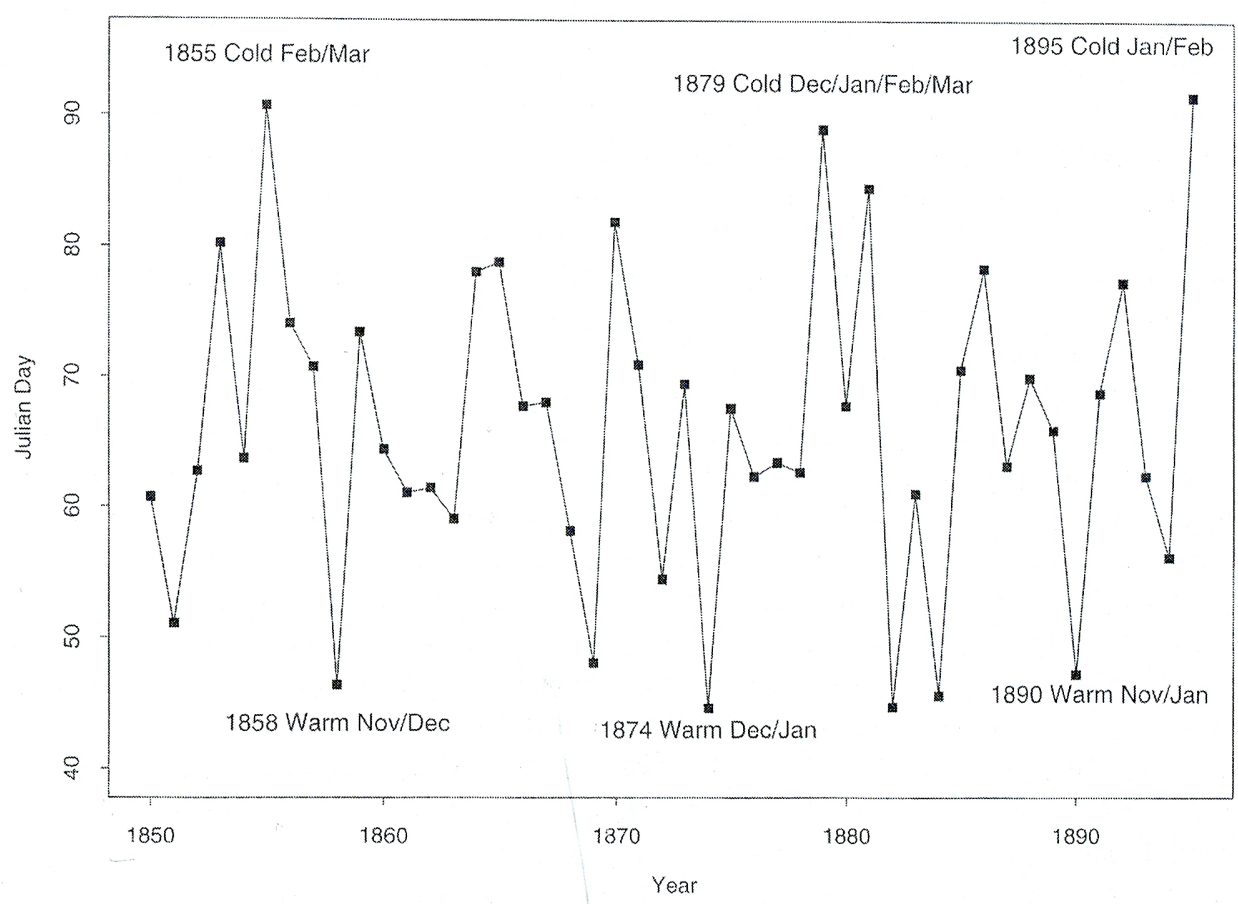

Figure 1. Average first flowering date for 66 taxa for the years 1850 through 1895. Notice how early years, like 1874, when flowering occurred in mid February (day 47), had particularly warm winters (especially the months of December and January). Late flowering years like 1895, when flowering was delayed until the start of April (day 92), are by contrast associated with noticeably cooler than average temperatures (especially in January and February). During the second half of the 1800s year-by-year changes led to mean flowering dates varying by about 45 days. In the coming century global warming is likely to cause temperatures to increase by over three degrees. This extra warmth (based on the inter-annual changes displayed here) is likely to advance first flowering dates by about 11 days for every degree $\left({ }^{\circ} \mathrm{C}\right)$ of rise.

On the initiative of Thompson and Mann, a new project based on daily monitoring was begun at RBGE in January 2002. Currently 250-300 accessions in the Garden are monitored daily in the period leading up to flowering. Once a plant has commenced flowering, it is generally not monitored regularly again until the corresponding period in the following season, unless a second flowering is expected. Since this 'daily' project measures only first-flowering dates, a second 'weekly' project is currently being set up, the aim of which is to monitor plants throughout the year on a weekly 
basis, in order to measure not only start but also end of flowering, and hence also flowering duration. A project of this type was run at RBGE from 1906 to 1938. Another has been conducted for 25 years by Professor Fred Last at Longniddry, which is $18 \mathrm{~km}$ east of RBGE and at about the same altitude and distance from the sea (Last 2001; Last et al. 2003).

\section{SELECTION OF SPECIES}

Early in 2002 the 'daily' RBGE project was set up, initially as a trial, to take advantage of the current season and to gain general experience. Species were selected for study based on a number of criteria. These included (a) temperature-sensitive species studied previously at RBGE during the 19th and 20th centuries; (b) Lonicera korolkowii and Syringa vulgaris cv. as used in an extensive American study (Cayan et al. 2001); (c) species included in the 'Kew 100' project recently begun at the Royal Botanic Gardens, Kew (http://www.kew.org/wild/phenology/); (d) species monitored by Professor Last; (e) native (UK) species as studied by Fitter et al. $(1995,2002)$ and/or included in the UK Phenology Network project; and (f) taxa of particular interest to RBGE, such as species of Rosaceae and Rhododendron.

One of the main themes of this article is that the amount of potentially useful work that can be undertaken in a phenological project at a botanic garden is almost limitless. Hence, the temptation is to be over-ambitious in relation to the frequency of recording and the number of taxa being studied. We recommend that, for maximum effectiveness, phenological projects in botanic gardens be ruthlessly realistic and targeted. Applying this maxim has already led us to rationalise our initial 'daily' project, concentrating on a shorter list of accessions, and to begin a less intensive 'weekly' project for other species, which will be easier to maintain by our volunteer recorders. The 'daily' project at RBGE now concentrates on (1) taxa monitored at the same site between 1850 and 1939, and (2) Scottish and other UK native species. At the end of 2003, 92 taxa were being monitored, of which 53 belong to group (1) and 29 to group (2).

\section{ORGANISM PHENOLOGY AND POPULATION PHENOLOGY}

At RBGE we make a distinction between organism phenology and population phenology. Organism phenology studies the phenological behaviour of the individual organism. This is easiest in the case of trees and shrubs, which can be studied individually and be clearly and permanently labelled with a unique number. This enables comparisons to be drawn between different years for a single organism of constant site and genetic composition. With other types of perennials, organism phenology becomes more difficult, and it is problematic in the case of annuals, except perhaps for apomictic taxa.

While organism phenology of some taxa may prove useful for studying climate, by virtue of the constant site and genetic status of the organism, it is well known that some plants do not behave consistently from year to year, even in the absence of significant variation in the external environment. The two-year cycle in flowering and fruiting of some apple cultivars, and the longer cycles in some mast trees (e.g. oak, Quercus, and beech, Fagus), are cases in point. One might also expect age effects, and of course effects of disease and variations in nutrition. 
Population phenology, on the other hand, involves collecting observations from populations, usually very large ones. In the case of the UK Phenology Network project, the population may cover the whole country. There are reasons for expecting population phenology generally to be more useful than organism phenology for climatology. For instance, in taxa where individuals tend not to behave consistently from year to year, as in the case of the apples mentioned above, a population will behave more consistently since 'weak performers', e.g. late flowerers, will not feature in measurements of first flowering. In addition, cyclical or quasi-cyclical variation is likely to be lost (unless of course it is synchronised through the population).

Another feature of population phenology may, however, diminish responsiveness to climate change. Selection effects are to be expected in taxa with a rapid turnover of individuals, such as annuals, biennials and short-lived perennials. While selection may involve thresholds and rates of response of a given switching mechanism determining, say, flowering date, it could also involve change from one switching mechanism to another one. Clearly there is the potential for a population to respond to external conditions in far more complicated ways than an individual long-lived organism, so that interpreting the results of population phenology may become highly problematic.

For example, a potential complication concerns genetic adaptation, whereby populations of annual plants may keep pace with environmental change, and so not show strong responses to climate change. However Etterson and Shaw (2001), amongst others, argue that rates of genetic evolutionary response are in practice likely to be much slower than the predicted rapid rates of climate change thought to be associated with global warming.

The organisation of a phenological project and the interpretation of its results must therefore take into account whether organism and/or population phenology is involved. The 'daily' project at RBGE uses a multiple-accession approach in which, so far as possible, at least three accessions of each monitored taxon are used, preferably sited in different parts of the Garden. Given $x$ accessions of a taxon, it is then possible to derive two extra parameters, in addition to the individual first-flowering dates of the $x$ accessions, namely the mean first-flowering date (mFFD) and earliest or absolute firstflowering date (aFFD). These are population-phenology parameters. In some cases (e.g. Prunus avium, Rhododendron yunnanense) seven or eight accessions are used to create a 'mini-population'. By this means it is hoped not only to study the organism phenology of these taxa, but also gain some insight into intra-taxon variation and population phenology, though with selection effects eliminated.

Such an approach is less easy with the mass plantings typically used for non-woody species, but the multiple-accession approach is used for them too, on security grounds. One problem with using a single accession for a taxon is that, if the plant is destroyed, damaged, or has to be moved, observations must be continued on a different plant, or on the same plant in a new environment, and that calls into question whether observations collected from different accessions or the same accession in different conditions can be combined for analysis. Even if a new plant is a clone of the old one, it may be of a different age, in a different physiological state, and/or at a different site. 


\section{CRITERIA FOR RECORDING FLOWERING AND OTHER PHENOLOGICAL PARAMETERS}

A scientific programme of observations must have objective criteria for making those observations. In other words, instructions must exist in writing and be followed in such a way that any two competent observers would make the observations in the same way and record the same results. It is to be regretted that we have not found any such instructions for observations made at RBGE up to 1939.

First-flowering date is a popular parameter among phenologists since it can generally be made objective. The standard first-flowering criterion used in the 'daily' project, as suggested by Prof. Last, is visibility of an anther or stigma in one flower, without manipulating the flower (e.g. by moving petals). For some taxa a derived criterion is also used, such as for first "mass" flowering; in the case of Forsythia it is 10 flowers on one bush showing stamen or stigma, and for Ribes sanguineum it is 10 inflorescences each with at least one flower showing stamen or stigma. Where a plant flowers sporadically over an extended period, e.g. all winter, the mass-flowering criterion may be more suitable for both climatological and horticultural purposes.

Special criteria need to be devised for some plants. In Fabaceae, for instance, the stamens and stigmas are never normally visible, and the criterion depends instead on separation of standard and keel petals; a similar criterion is used for Corydalis and Dicentra. Some plants have flowers which may open very slowly (e.g. Choisya ternata, Chaenomeles japonica), while others open and close according to the prevailing weather (e.g. Sanguinaria canadensis, Anemone blanda); in such cases, finding a practical objective criterion is difficult and perhaps impossible.

Observations were made in 2003 and 2004 on a number of trees (Malus, Pyrus) with regard to aspect. First flowering was recorded separately for the south and north sides of each tree, with a view to investigating bud-temperature effects. To make such observations objective, it must be stipulated which part of a tree constitutes the "north side' and which the 'south side'.

\section{EXTENSIVE AND INTENSIVE PHENOLOGY}

The 'daily' project at RBGE is extensive, in so far as a large number of taxa are monitored, but only one parameter is measured. This is appropriate for a project geared to a particular purpose, such as the search for indicators of climate change.

Other purposes may require a more intensive approach, studying more parameters on fewer taxa. Any serious study of a species' response to its environment would require an intensive approach. Tests are currently being conducted at RBGE on one specimen of Malus sieboldii with a view to developing objective measures of budburst, beginning and end of shoot elongation, and leaf fall. An objective measure of fruit ripening has not yet been found. Incidentally, first flowering causes some problems in this and some other Malus species, since the stigma may protrude from an otherwise apparently unopened bud, with subsequent stages of opening being gradual and protracted. Though visibility of the stigma is still the best criterion, it requires a careful search of many buds since the stigma is small and no petal colour may be showing. 


\section{EFFECTS OF SOIL TEMPERATURE}

In 2003 a subsidiary project was set up within the 'daily' monitoring programme to investigate the effects of soil temperature and microclimate on the flowering of six species of European bulbs. At each of six extreme sites in the Garden, selected to provide differences in shading, soil moisture and temperature, half of a Latin square was laid out, involving three rows of six baskets, in each of which was planted one bulb at a fixed depth. Each 'thermistor plot' has the same six species (autumnflowering Crocus speciosus, and spring-flowering $C$. vernus, Galanthus nivalis, Narcissus minor, N. pseudonarcissus, Scilla bifolia) with replication 3. European bulbs were chosen from a wide list of potential taxa, ranging from shrubs to alpines, as being (i) temperature-sensitive when observed in both the 19th and 20th centuries, (ii) species for which RBGE could provide clonal material, (iii) likely to thrive (or at least survive) in the six extreme microclimates and (iv) not overly obtrusive when inserted into the established RBGE plantings. At each site are buried logging thermistors which record the soil temperature every three hours at depths of 10,20 and $30 \mathrm{~cm}$. The thermistors are housed in small plastic containers (Nivea tubs) and can be left in place for up to five years. The aim is to look for soil-temperature effects on first-flowering date independent of air temperature. For example it has already been noticed that Ranunculus ficaria flowers much earlier in the open than in woodland, the difference being 47 days in 2002 and 49 days in 2003, and this may be related to soil temperature.

\section{OTHER PROJECTS AND STUDIES}

Given record temperatures continuing to be set around the world and the ensuing interest in climate change, phenology has taken on a new lease of life. The interest arises because it is realised that phenological records of year-by-year variations allow the sensitivities of plants and animals to a wide range of environmental factors to be established. Such responses to inter-annual changes can in turn be used to predict the likely impact of climate change in the coming decades (see caption to Figure 1). A good example of yet another climatic extreme occurred while this article was being written: the Meteorological Office confirmed that the Scottish maximum temperature record was broken on 9 August 2003 when Greycrook near St Boswells reported a maximum of $32.9^{\circ} \mathrm{C}$ - beating the previous record at Dumfries on 2 July 1908 .

A considerable number of other phenology programmes have recently been established, several of which have influenced the design of the RBGE 'daily' project. Perhaps closest to RBGE's 'daily' project is RBG Kew's 'Kew 100'. It involves monitoring 100 species, with one accession of each, in the continuation of a private initiative conducted from the 1950s by Nigel Hepper while he was a member of staff. Another project run as a private initiative was the long-term study by Richard Fitter, monitoring 243 species over a wide area of central England, centred on Oxford, from 1954 to 1989 (Fitter et al. 1995; Fitter \& Fitter, 2002). Unlike the botanic garden projects, this work was concerned entirely with population phenology.

Also using the population approach, but involving mass participation by the general public, are the American study reported on by Cayan et al. (2001) and the UK Phenology Network project (website www.phenology.org.uk). Inevitably with participation by numerous observers not known personally to the organisers, quality 
control of monitoring becomes more difficult, although the mass appeal and broad educational value is enhanced.

Yet other approaches to phenology are (a) to tackle the problem of genetic heterogeneity within each monitored taxon, and (b) to extend observations over a much wider area. An attempt to cater for (b) has been undertaken in the zapovednik (strict scientific nature reserve) system of the Soviet Union, and now the Russian Federation, since the 1930s: in the 'Chronicle of Nature' programme, more or less standardised phenological and other annual observations are conducted, and this has enabled comparisons to be made over extensive areas of the largest country in the world (Kokorin et al., 2001; Shtil'mark, 2003). Both approaches (a) and (b) are catered for in the International Phenological Garden (IPG) project (website www.agrar.huberlin.de/pflanzenbau/agrarmet/ipg_hist.html), which involves the supply of genetically uniform material (mostly trees) from the headquarters in Germany to suitable gardens across a large part of northern Europe.

Given this diversity of principle and practice, it is important to note that phenological results from different projects are not always comparable. Not only may different observational criteria be used, e.g. for recording first flowering, but organismphenological data are in principle different in kind from population-phenological data: for instance, at RBGE, the first flowering of a given taxon will not be recorded if the plant flowering first happens not to be on the list of monitored accessions.

\section{SUITABILITY OF BOTANIC GARDENS FOR PHENOLOGY}

The fact that botanic gardens contain a large number of species - usually correctly identified, labelled, documented and well cared for - gives them many advantages as sites for phenological projects, particularly organism phenology. They are also well suited to the long-term commitment implicit in phenology by generally being stable institutions with infrequent changes in organisation. Other advantages offered by some gardens are their own in-house research facilities or links with a local university, onsite meteorological station, propagation facilities and expertise (especially where cloned material is required), and expertise in checking the identification of plants in the living collection. RBGE enjoys all these features.

To take one example, the aim may be to investigate certain phenological characters for their value in taxonomy, e.g. relative flowering and leafing dates. For instance, the approximate flowering period is constant within each of the majority of multi-species sections in the genus Crocus (Mathew, 1982). Gardens holding national collections of the taxa in question would clearly be strong candidates as sites for such a project.

A project designed to survey plants as potential climate-change indicators would be organised in a manner similar to the 'daily' project at RBGE - namely, extensive, and measuring the parameters believed to be particularly responsive to weather. On the other hand a project concerned with the effects of plants on climate might concentrate on ecologically important species, e.g. forest dominants, and measure relevant parameters such as bud-burst, leaf fall and productivity that relate to $\mathrm{CO}_{2}$ drawdown. An example is the IPG programme.

If the focus of attention is the timing of public events or the seasonal opening and closing of gardens, species and cultivars important as visitor attractions would be monitored for timing and duration of flowering and foliage colour. 
A group of commercially important plants, such as fruit trees, might be the centre of attention, including their adaptation to changing climate. Just as domestic apples are being improved by the introduction of genes for resistance to various diseases and tolerance of low winter temperatures from wild species such as Malus baccata and M.hupehensis and from some hybrids (Fraser, 2003), other phenologically important variables could be studied in the wild relatives of Malus and other horticulturally important taxa with a view to finding genes potentially capable of improving cultivars in the context of changing climate. To that end the RBGE 'daily' project is monitoring Malus baccata, $M$. floribunda, $M$. hupehensis, $M$. kansuensis and $M$. sieboldii, and it is expected soon to add $M$. sieversii. The Malus baccata 'Hiemalis' (RBGE Accession number 1903.1006) is of particular interest as its flowering was already being monitored in the early 1900s. The RBGE records show that 1903.1006 was brought as a seedling from Germany in 1903.

Ecological studies might require monitoring of plant parameters together with the behaviour of pollinators, pests or other organisms ecologically important in the life cycle of the plants. A conservation-oriented project could concentrate on threatened plants of the local area (e.g. rare Scottish alpines, in the case of RBGE) with a view to finding out more about how to conserve the plants in their remaining natural sites.

It is worth noting that a phenological research programme can be mounted comparatively cheaply, if observations are made by volunteers alongside horticultural staff working in the garden. It must be emphasised, however, that training will normally be required for personnel not already scientifically qualified, to ensure a high standard of consistent and accurate observation and recording.

There could be several benefits to botanic gardens in becoming involved in phenology. Given the public interest in climate change - an interest which is likely to be long-term - botanic gardens could generate valuable publicity if they acquire a new role as environmental monitoring stations. By using a carefully selected set of taxa, distributed through the seasons in such a way that an adequate number come into flower each fortnight or month, a botanic garden could calculate and publicise an 'earliness-of-spring' index during the first half of each year, based on the long-term average proportion of the list that has flowered by any given date.

As well as providing information useful to local gardeners and of general public interest, a botanic garden could also promote local involvement by encouraging people living in the vicinity to make their own observations, which the garden would then collate and publish. In the case of Edinburgh, maps could be produced and used to determine which are the 'early' and 'late-flowering' parts of the city, in relation to altitude, aspect, soil type and proximity to the sea.

\section{ACKNOWLEDGEMENTS}

We offer our thanks to Ken Anderson, Alan Bennell, Pete Brownless, David Chamberlain, Rob Cubey, Graham Hardy, Stephan Helfer, Sally Heron, Fred Last, Janette Latta, Clare Morter, Leonie Paterson, David Rae, Robert Unwin, R.T.'s students, and many others for help and encouragement. We also acknowledge assistance from the Moray Endowment Fund (administered by the University of Edinburgh), which financed the thermistors and planting baskets. 


\section{G.H. HARPER, D.G. MANN \& R. THOMPSON}

\section{REFERENCES}

ANON. (1765). List of plants growing in the neighbourhood of Edinburgh collected in flower 1765 as a sketch of the Calendarium Florae of Edinburgh. MS in the Library of RBGE, published 1907 in Roy. Bot. Garden [Edinburgh] Notes IV: 123-146.

BALFOUR, J.H. (1861). Observations on temperature in connection with vegetation [...]. Trans. of the Botanical Society [of Edinburgh] vii (1): 58-92.

BUCHAN, A. (1875). Bearing of meteorological records on a supposed change of climate in Scotland. Transactions and Proceedings of the Botanical Society of Edinburgh 12: 250-253.

CAYAN, D.R., KAMMERDIENER, S.A., DETTINGER, M.D., CAPRIO, J.M. \& PETERSON, D.H. (2001). Changes in the onset of spring in the western United States. Bulletin of the American Meteorological Society 82(3): 399-415.

ETTERSON JR, SHAW RG. 2001. Constraint to adaptive evolution in response to global warming. Science 294, 151-54

FITTER, A.H. \& FITTER, R.S.R. (2002). Rapid changes in flowering time in British plants. Science 296: 1689-1691.

FITTER, A.H., FITTER, R.S.R., HARRIS, I.T.B. \& WILLIAMSON, M.H. (1995).

Relationships between first flowering date and temperature in the flora of a locality in central England. Functional Ecology 9: 55-60.

FRASER, J.E. (2003). Biology of Apples and Pears. Cambridge University Press.

GUNN, H. (2003). Tidal movements. The English Garden January 2003, 90.

KOKORIN, A.O., KOZHARINOV, A.V. \& MININ, A.A. (eds.) (2001). Climate Change Impact on Ecosystems. Moscow: Russkiy Universitet. (In Russian and English.)

LADURIE, E. Le R. \& BAULANT, M. (1981) Grape harvest from the fifteenth through the nineteenth century In: Climate and History: Studies in interdisciplinary history. Eds. Robert I. Rotberg and Theodore K. Rabb. Princeton University press. New Jersey.

LAST, FRED (2001). Keeping records. The Horticulturist Spring 2001, 9-11.

LAST, F., ROBERTS, A., \& PATTERSON, D. (2003). Climate change? A statistical account of flowering in East Lothian: 1978-2001. In East Lothian Fourth Statistical Account 1945-2000, [publisher].

LINDSAY, R. (1893). On temperature and vegetation in the Royal Botanic Garden, Edinburgh, during the month of April 1893. Transactions and Proceedings of the Botanical Society of Edinburgh 19: 602-605.

LINNAEUS, C. (1751). Philosophia Botanica. Translation by Stephen Freer, published as Linnaeus' Philosophia Botanica, Oxford University Press, 2003.

MATHEW, B. (1982). The Crocus. London: B.T.Batsford.

McNAB , J. (1857). Register of the flowering of certain plants in the Royal Botanic Garden, from $1^{\text {st }}$ February till $12^{\text {th }}$ March 1857, compared with the five previous years. Transactions and Proceedings of the Botanical Society of Edinburgh 5: 173.

McNAB, J. (1873). Presidential address. Transactions and Proceedings of the Botanical Society of Edinburgh 12: 1-18. 
MENZEL, A. \& FABIAN, P. (2001). Climate change and the phenology of European trees and shrubs. Pp.47-52 in: Green, R.E., Harley, M., Spalding, M. \& Zöckler, C. Impacts of Climate Change on Wildlife, RSPB for English Nature, WWF-UK, UNEP World Conservation Monitoring Centre, \& RSPB.

MURRAY, M.B., CANNELL, M.G.R. \& SMITH, R.J. (1989). Date of bud-burst of fifteen tree species in Britain following climatic warming. J.Applied Ecology 26: 693-700.

SADLER, J. 1879. Report on temperatures during the winter of 1878-79 at the Royal Botanic Garden, Edinburgh; effects of the same on open-air vegetation at the Garden and in other parts of Scotland; table of dates of flowering of spring plants. Transactions and Proceedings of the Botanical Society of Edinburgh 13: 470-487.

SADLER, J. 1882. Note on table of flowering of plants in the Royal Botanic Garden, Edinburgh, from 1850 to 1882. Transactions and Proceedings of the Botanical Society of Edinburgh 14: 374.

SHTIL'MARK, F.R. (2003). History of the Russian Zapovedniks 1895-1995. Edinburgh: Russian Nature Press. 
